\title{
Optimizing Substrate Moisture Measurements in Containerized Nurseries
}

\author{
Alex B. Daniels and David M. Barnard \\ Department of Horticulture and Landscape Architecture, Colorado State \\ University, 1173 Campus Delivery, Fort Collins, CO 80523-1173
}

Phillip L. Chapman

Department of Statistics, Colorado State University, Fort Collins, CO 805231877

\author{
William L. Bauerle ${ }^{1}$ \\ Department of Horticulture and Landscape Architecture, Colorado State \\ University, 1173 Campus Delivery, Fort Collins, CO 80523-1173
}

Additional index words. irrigation, pot-in-pot, sample size, sensor variability, tree production, volumetric water content

\begin{abstract}
The primary goal of this study was to determine the optimum number of substrate moisture sensors needed to accurately determine substrate water content for 10 tree species in a containerized nursery. We examined variation in volumetric water content $\left(\mathrm{VWC}, \mathrm{m}^{3} \cdot \mathrm{m}^{-3}\right)$ within containers, within species, among species, and over time. Across time, differences among species were not significant $(P=0.14)$. However, differences among time periods and the interaction effect between species and time periods were significant $(\boldsymbol{P}<\mathbf{0 . 0 0 1})$. Seasonal differences in within-species variation were also evident in nine of the 10 species. In an attempt to understand species-specific mechanistic factors that influence within-species variation in VWC, we accounted for physiological and morphological differences affecting transpiration with a spatially explicit mechanistic model, MAESTRA. Neither estimated transpiration rate per whole crown or $\mathrm{m}^{2}$ of leaf area could explain variation in VWC. Based on our results, we recommend species-specific sensor deployment and report sensor quantities that estimate the mean substrate VWC of each species within a confidence interval of $\pm \mathbf{5 \%}$ VWC. Given the economic value of water and its control on biomass production, we conclude that nursery managers can maintain optimal substrate moisture with minimal sensor deployment.
\end{abstract}

Substrate moisture is an important component of crop water status because it controls the partitioning of water and energy fluxes. In container-grown production systems, the volume of water that can be held in the rhizosphere is restricted, and effective irrigation is required to replace water lost through transpiration and surface evaporation. Quantifying the amount of water to be

Received for publication 5 Oct. 2011. Accepted for publication 21 Nov. 2011.

We thank Willoway Nursery and its staff for donating the trees, site, and assistance for this study. We also thank George Kantor, David Kohanbash, and their team at Carnegie Mellon University for their work on the wireless node network used in this study. We thank the following funding agencies for partial support of this study: U.S. Department of Agriculture-National Institute of Food and Agriculture, Specialty Crops Research Initiative Grant (Award No. 2009-51181-05768) and U.S. Department of Agriculture-Floriculture Nursery Research Initiative, Cooperative Agreement (Agreement No. 58-6618-2-0209). Decagon Devices Inc. subsidized equipment costs in Award No. 2009-51181-05768.

${ }^{1}$ To whom reprint requests should be addressed; e-mail bauerle@colostate.edu. replaced requires accurate characterization of the availability of water within the container and the rate of plant water use (Vereecken et al., 2008). These values may differ within individual containers, from one container to the next, and among species within a nursery. A review of the literature reveals that there is a paucity of data to address the variability of substrate moisture among species grown in nursery containers. For example, Williams (1978) found substrate moisture to increase with container depth; however, it was undetermined if the relationship persisted or varied among species. Most importantly, previous studies fail to fully report the variation in substrate moisture among nursery containers of the same species, leaving the measurement sample size for adequate substrate moisture characterization within and among populations unknown. Consequently, there is a need to investigate substrate moisture variation among containers of the same species and among groups of different species in an intensively managed containerized nursery.

Over the past decade, relatively inexpensive substrate moisture sensors have become commercially available (e.g., Decagon Inc. Model EC-5; Irrometer Inc. Model Watermark 200SS). By logging the sensors with wireless nodes, substrate moisture data can be broadcast throughout a horticulture operation and transmitted to a base station linked to the World Wide Web (e.g., Rundel et al., 2009). Access to live substrate moisture data creates the potential to automate irrigation according to species-specific demand. A relatively straightforward approach involves defining a desirable range of substrate moisture, below which irrigation is initiated and above which irrigation ceases. A more mechanistic method could use substrate moisture data to validate speciesspecific transpiration model predictions, thus providing a real-time assessment of model performance. Regardless of the specific implementation, the ability to remotely monitor substrate moisture in real-time allows for better informed irrigation management decisions.

Although the technological advances are an important achievement, deploying substrate moisture sensors in container-grown plant material presents a unique challenge as compared with field placement. At the container scale, substrate moisture content is directly affected by the rate of root water uptake, which is primarily driven by the rate of leaf-level transpiration and the total transpiring leaf area. Furthermore, root density distribution, a variable that can be species-dependent, and substrate surface evaporation affect water extraction patterns (Andreu et al., 1997; Coelho and Or, 1998; Hupet and Vanclooster, 2005), potentially confounding the placement of substrate moisture-monitoring devices. A discontinuous medium (e.g., substrate within isolated containers) also prevents the use of spatial interpolation techniques and requires estimating substrate moisture from a population of individuals (the containers) rather than as a continuous function across a field. Given the relatively small volume of water accessible to plants in containers, these estimates must be precise to effectively maintain suitable substrate moisture levels. The precision of substrate moisture estimates can be improved with additional sensors, but an economically practical implementation requires a balance between cost concerns and sufficient sampling.

The objective of this study was to assess substrate moisture variation in container-grown plant material and determine an optimum sensor deployment accordingly. Specifically, we analyzed the variation in substrate moisture within individual containers, within blocks of trees of the same species, among groups of different species, and explored the change in within-species substrate moisture variation over time. We tested the hypothesis that the optimum number of substrate moisture sensors varies among species and changes with time. After establishing the amount of withinspecies variation in measured substrate moisture, we determined the number of substrate moisture sensors required to accurately estimate mean VWC $\left(\mathrm{m}^{3} \cdot \mathrm{m}^{-3}\right)$ for each study species within a $95 \%$ confidence interval no wider than $\pm 5 \%$ VWC. To investigate the contributions of species-specific morphological and physiological transpiration factors that might influence variation in substrate 
moisture within a species, we used the threedimensional spatially explicit individual plant process model MAESTRA (Multi-Array Evaporation Stand Tree Radiation Assay) (Wang and Jarvis, 1990a). The modeling analysis attempts to isolate and quantify different deterministic sources of VWC variability.

\section{Materials and Methods}

Site description and plant material. On 1 May 2010, 10 experimental plots, each separated by a $2.5-\mathrm{m}$ wide tractor alleyway, were established within a 1-ha parcel at Willoway Nurseries Inc. L.L.C. in Avon, OH (lat. $41^{\circ} 25^{\prime} 30^{\prime \prime} \mathrm{N}$, long. 82²'59" W). Each species-specific plot contained 250 trees or more spaced $1.5 \mathrm{~m}$ center-to-center. We chose these 10 species: Acer rubrum L. 'Franksred' (A. rubrum), Acer saccharum L. 'Green Mountain' (A. saccharum), Betula nigra 'Cully' (B. nigra), Carpinus betula 'Columnaris' (C. betula), Cercis canadensis ( $C$. canadensis), Gleditsia triacanthos var. inermis 'Skycole' (G. triacanthos), Magnolia stellata 'Royal Star' (M. stellata), Platanus acerifolia 'Bloodgood' (P. acerifolia), Quercus rubra L. (Q. rubra), and Thuja standishii $\times$ plicata 'Green Giant' ( $T$. plicata) for their physiological variety and their popularity in containerized commercial nursery production (T. Demaline, personal communication). Trees were first-year whips (without side shoots), except for $Q$. rubra, which was beginning the second containerized year. At the beginning of the study, all trees had been in containers for no less than 3 months after transplant. Mean heights for each species at the beginning of the study were: $A$. rubrum, $206 \mathrm{~cm}$; A. saccharum, $247 \mathrm{~cm}$; B. nigra, $100 \mathrm{~cm}$; C. betula, $145 \mathrm{~cm}$; C. canadensis, $207 \mathrm{~cm} ; G$. triacanthos, $208 \mathrm{~cm}$; M. stellata, $93 \mathrm{~cm} ; P$. acerifolia, $175 \mathrm{~cm}$; Q. rubra, $265 \mathrm{~cm}$; and $T$. plicata, $78 \mathrm{~cm}$. Five to seven replicate containers per plot ( $\mathrm{n}=5$ or 7 ) were randomly selected for repeated sampling of substrate moisture. Monthly, each sample tree was measured for height and stem diameter. Growth index $\left(\mathrm{GI} ; \mathrm{cm}^{2} \cdot \mathrm{m}^{-1}\right)$ was calculated from stem diameter $(\mathrm{cm})$ squared times total plant height $(\mathrm{m})$ and linearly interpolated between time points (Fig. 1). Leaf area index (LAI) values were measured in conjunction with GI (Model LAI 2000; LI-COR Inc., Lincoln, NE) and linearly interpolated between time points. All trees were grown potin-pot in 57-L containers $(44 \mathrm{~cm}$ in diameter and $38 \mathrm{~cm}$ deep) containing a mixture of $64 \%$ pine bark, $21 \%$ peatmoss, $7 \%$ Haydite, and $7 \%$ sterilized regrind potting soil. The remaining $1 \%$ was slow-release fertilizer 12-0-42 (Agrozz Inc., Wooster, OH). Substrate physical properties were measured using methods outlined by Klute (1986). The physical properties of the substrate fit within the best management practice (BMP) guidelines outlined by Yeager et al. (2007): waterholding capacity of $56.3 \%$ (BMP $=45 \%$ to $65 \%)$, air space of $10.7 \%(\mathrm{BMP}=10 \%$ to $30 \%)$, total porosity of $67.0 \%(\mathrm{BMP}=50 \%$ to $85 \%)$, and bulk density of $0.35 \mathrm{~g} \cdot \mathrm{cm}^{-3}(\mathrm{BMP}=0.19$ to $\left.0.70 \mathrm{~g} \cdot \mathrm{cm}^{-3}\right)$. Individual containers were irrigated with a single spray stake (Netafim Inc., Israel) placed $\approx 5 \mathrm{~cm}$ inward from the outside edge of the container. The spray stakes applied water in a $180^{\circ}$ fan toward the center of the container. All containers were irrigated twice daily at $600 \mathrm{HR}$ and $1800 \mathrm{HR}$ for $5 \mathrm{~min}$ at a flow rate of $12 \mathrm{~L} \cdot \mathrm{h}^{-1}$ resulting in a daily application of $2 \mathrm{~L}$ per container. Spray stakes were checked continuously throughout the experiment to ensure emitters were not clogged or emitting water outside the container.

Substrate moisture measurements. Substrate VWC was measured in each container with model 5TM sensors (Decagon Devices Inc., Pullman, WA). The sensors have a $0.3-\mathrm{L}$ volume of influence and are $\approx 5 \mathrm{~cm}$ long and $3 \mathrm{~cm}$ wide. The 5 TM model uses frequency domain/capacitance to measure the dielectric permittivity $\left(\varepsilon_{\mathrm{a}}\right)$ of the substrate. The sensors were calibrated to the specific substrate used in the study following the general procedure for calibrating capacitance sensors outlined by Starr and Paltineanu (2002) in which a series of $\varepsilon_{\mathrm{a}}$ measurements are taken in conjunction with volumetric soil samples to quantify the non-linear relationship between substrate $\varepsilon_{\mathrm{a}}$, measured with the 5TM, and VWC. In the nursery, one sensor was installed $\approx 20 \mathrm{~cm}$ below the substrate surface in the geometric center of each sampled container. Additionally, in one randomly selected container per species, two more sensors were installed, one above and one below the original sensor, at depths of 10 and $30 \mathrm{~cm}$ below the substrate surface to measure the vertical substrate moisture profile. All sensors were inserted into position through a circular hole, $3 \mathrm{~cm}$ in diameter, drilled into the side of the container. Sensors were sampled at 1-min intervals and 5-min averages were computed and stored (Em50R; Decagon Devices Inc.) from 21 May to 15 Sept. 2010.

Meteorological measurements. Photosynthetic photon flux $\left(P P F ; \mu \mathrm{mol} \cdot \mathrm{m}^{-2} \cdot \mathrm{s}^{-1}\right)$, precipitation $(\mathrm{R} ; \mathrm{mm})$, wind speed $\left(\mathrm{W}_{\mathrm{s}} ; \mathrm{m} \cdot \mathrm{s}^{-1}\right)$, air temperature $\left(\mathrm{T}_{\text {air }} ;{ }^{\circ} \mathrm{C}\right)$ and relative humidity (RH; \%) were measured once per minute using QSO-S PAR photon flux sensors, ECRN-100 high-resolution rain gauges, Davis cup anemometers, and EHT Rh/Temperature sensors respectively (Decagon Devices). Sensors were mounted above the canopy on a fixed post $\approx 3 \mathrm{~m}$ above the ground in the center of each plot. Data from each plot was averaged and stored every $5 \mathrm{~min}$ with a Decagon data logger (Decagon Model 50R). Averages of all plots were used in subsequent analysis. Figure 2 illustrates the pattern of meteorological variables over the course of the study (May to September) along with the FAO-56 Penman-Monteith reference evapotranspiration $\left(\mathrm{ET}_{\mathrm{o}}\right)$, mean vapor pressure deficit $(\mathrm{kPa})$ and mean daily photosynthetically active radiation $(P A R$; $\mu \mathrm{mol} \cdot \mathrm{m}^{-2} \cdot \mathrm{s}^{-1}$ ).

Data analysis. Two repeated-measures analyses of variance (ANOVA) were conducted to examine variability in substrate moisture.

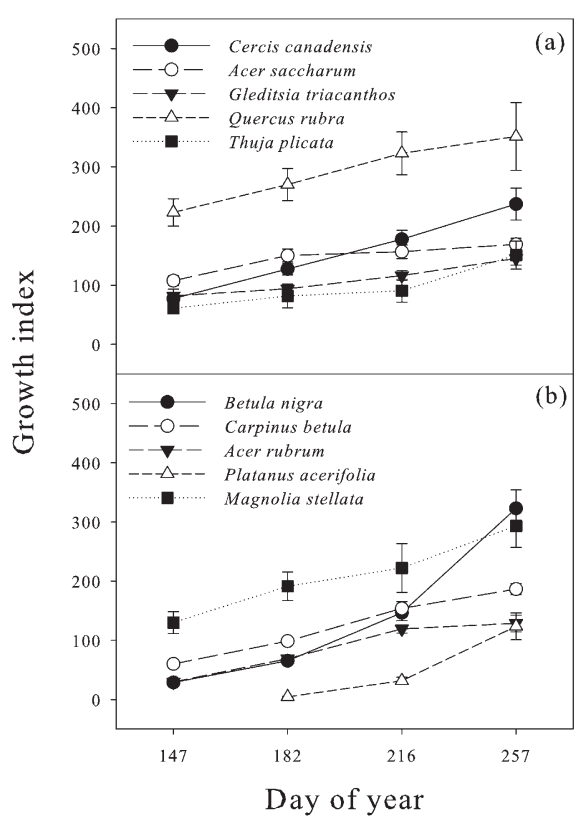

Fig. 1. Growth index $\left(\mathrm{cm}^{2} \cdot \mathrm{m}^{-1}\right)$ [stem diameter $(\mathrm{cm})$ squared times total plant height $(\mathrm{m})]$ plotted over the course of the study (May to September). Each species is depicted by an independent symbol and line defined on each panel (A or B). Note, Platanus acerifolia growth index is absent on day of year 147 as a result of delayed growth.

Together these analyses seek to describe the ways in which substrate moisture may vary among species and over time in a containerized nursery. The first ANOVA, on VWC averaged over 2-week periods, used species as the grouping factor, container within species as subject, and eight time periods. The second ANOVA, on VWC averaged over monthly time periods, was conducted using the same design except with four time periods. Error variance in both analyses was modeled with an autoregressive heterogeneous variance design allowing variances to differ by time period. The autoregressive error structure models error correlations using an exponentially decreasing correlation $\left(\rho^{\kappa}\right)$ that decreases as the number of intervals

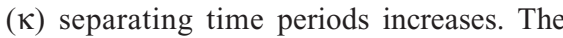
Satterthwaite method was used to estimate the degrees of freedom. Both the biweekly and monthly time scales investigate general trends across the growing season by averaging out daily or intradaily fluctuations. Levene's test for equality of variances was conducted to verify the assumptions of ANOVA and to compare differences in within-species variance over time. Computations for all ANOVAs were made using the MIXED procedure in SAS software Version 9.2 (SAS Institute Inc., Cary, NC). The autoregressive error structure was specified with the type $=$ ARH(1) option to the REPEATED statement. To visualize changes in within-species variation over time, the $\mathrm{CV}$ was estimated for each species at each 2 -week time period. These values were plotted over the course of the season. 


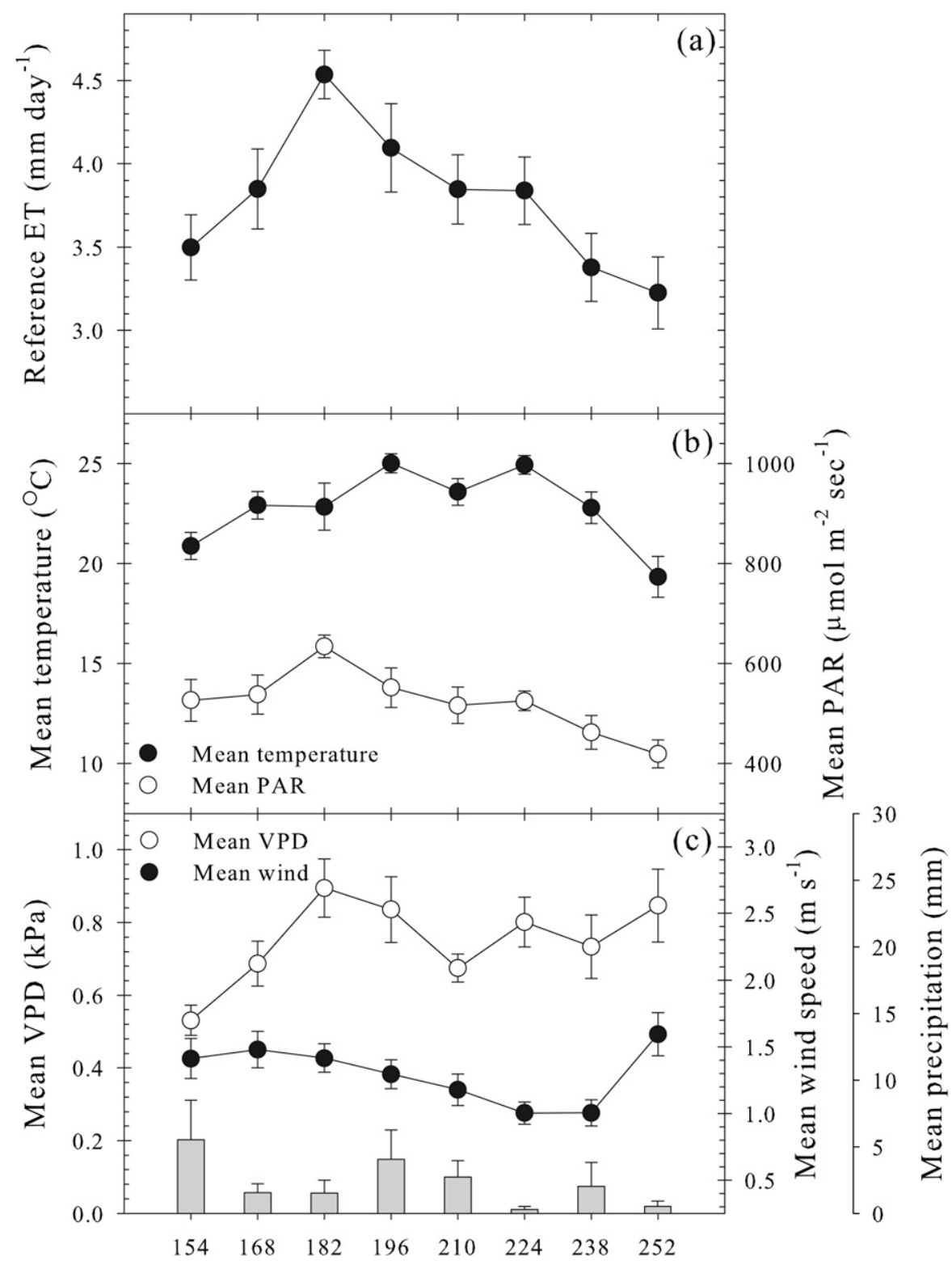

Day of year

Fig. 2. Biweekly averages of meteorological data over the course of the study (May to September): (A) reference evapotranspiration $\left(\mathrm{mm} \cdot \mathrm{d}^{-1}\right)$ calculated from the FAO-56 Penman-Monteith equation; (B) mean air temperature $\left({ }^{\circ} \mathrm{C}\right)$ and mean photosynthetically active radiation $\left[P A R\left(\mu \mathrm{mol} \cdot \mathrm{m}^{-2} \cdot \mathrm{s}^{-1}\right)\right]$; (C) mean vapor pressure deficit (VPD; $\mathrm{kPa})$, mean wind speed $\left(\mathrm{m} \cdot \mathrm{s}^{-1}\right)$, and mean daily precipitation $(\mathrm{mm})$.

After assessing the effects of species and time on VWC, we calculated the number of sensors necessary to limit daily $95 \%$ confidence intervals (CIs) for VWC to $\pm 5 \%$ for each species. These limits were chosen based on a sensitivity analysis of species response to soil moisture (Bowden and Bauerle, 2008). We iteratively solved Eq. (1) for $n$, sample size per species, until a stable solution was reached:

$$
t_{.025} \frac{s_{v w c}}{\sqrt{n}}=0.05
$$

where $t_{.025}$ is the upper quantile of the Student's $t$ distribution with $n-1 \mathrm{df}, s_{v w c}$ is the daily sample standard deviation of VWC, and the 0.05 corresponds to the chosen $\mathrm{CI}$ equation using daily averages of meteorological data. The MAESTRA model (see subsequently) was used to estimate transpiration in each species.

Model description and parameterization. MAESTRA is a three-dimensional processbased model that computes transpiration, photosynthesis, and absorbed radiation within an array of individual tree crowns. The primary purpose of using MAESTRA in this study was to scale up to the canopy level on a speciesby-species basis and describe the effects of climate on species-specific transpiration flux. Specifically, the model's three-dimensional spatially explicit nature and ability to parameterize species-specific morphology and physiology were critical. The model was parameterized for each species' leaf-level morphology, physiology, LAI, and growth changes on a monthly basis (May to September).

The light transfer portion of the model was previously validated in deciduous species against three independent $P A R$ measurement techniques (Bauerle and Bowden, 2004), whereas Wang and Jarvis (1990b) were the first to validate the light transfer for conifer species. A detailed description of how MAESTRA calculates light distribution and associated references is given in Bauerle et al. (2004).

Species-specific parameter values used by the photosynthesis and stomatal conductance $\left(g_{\mathrm{S}}\right)$ submodels within MAESTRA were those reported to have a $5 \%$ or greater influence on transpiration (Bauerle and Bowden, 2011a). Hence, differences between species transpiration were quantified by parameters within the coupled $\mathrm{CO}_{2}$ and $\mathrm{H}_{2} \mathrm{O}$ models of Ball et al. (1987) and Farquhar and von Caemmerer (1982) where transpiration of each subvolume of the crown was calculated by applying Ball et al. (1987) $g_{\mathrm{S}}$ estimates to an inverse form of the Penman-Monteith equation (Medlyn et al., 2007). Therefore, whole canopy transpiration estimates are merely the sum of each individual crown's subvolume estimates.

Model application. MAESTRA's application in this study is grounded in the work of others where the model has been described in detail, validated, and used to estimate transpiration in numerous conifer and deciduous species (Bauerle and Bowden, 2011a, 2011b; Bauerle et al., 2002, 2004, 2007, 2009; Bowden and Bauerle, 2008; Medlyn et al., 2007; Reynolds et al., 2009; Wang and Jarvis, 1990a, 1990b). Thus, each species' genetic differences were accounted for with speciesspecific parameters used in control equations to predict species-specific transpiration. MAESTRA meteorological input data- $P P F$, $\mathrm{T}_{\text {air }}, \mathrm{RH}$, and $\mathrm{W}_{\mathrm{s}}$-were based on 5-min averages of meteorological data. All MAESTRA calculations were made on a 5-min time step.

Vertical moisture profile. Measurements from the vertical sensor array in each plot were used to construct a seasonal vertical moisture profile. We calculated seasonal means for each sensor depth by pooling all species together. We linearly regressed VWC against sensor depth and used a lack of fit test to verify the linearity. 


\section{Results}

Although representing different time scales, the ANOVAs on both the biweekly and monthly mean VWC estimates showed essentially the same results. A significant interaction effect between species and time periods for both the biweekly $(P<0.0001)$ and monthly $(P=0.0002)$ ANOVAs indicates that changes in mean VWC over time differed depending on the species (Fig. 3). The similarity of results between the two ANOVAs shows that the interaction was not dependent on the time scale of the analysis. Plots of residuals vs. predicted values for both the biweekly and monthly models indicate no increase in variability with higher predicted values.

Levene's test of homogeneity of variances indicated significant differences $(P<0.05)$ in within-species variance for five of the eight 2-week time periods. Although this represents a violation of the assumptions of ANOVA, the general F-test is known to be fairly robust against such violations (Ott and Longnecker, 2001). The variability in substrate moisture within species not only differed among species but also changed over time. In six of the 10 species ( $B$. nigra, C. betula, $P$. acerifolia, $G$. triacanthos, M. stellata, and T. plicata), within-species VWC variation increased over time (Fig. 4). The remaining four species showed either a stable or decreasing amount of variability over time (Fig. 4). GI showed moderate to strong positive correlations with $s_{\mathrm{Vwc}}$ in six of the 10 species (B. nigra, $C$. betula, $P$. acerifolia, $G$. triacanthos, $M$. stellata, and T. plicata) (Table 1). However, neither LAI, $\mathrm{ET}_{\mathrm{o}}$, whole crown transpiration, nor transpiration per $\mathrm{m}^{2}$ showed a consistent correlation with $s_{\mathrm{Vwc}}$ among species (Table 1). We did not observe a change in within-species variation during or after precipitation events. The lack of response to additional irrigation through precipitation suggests that these results would not change at higher VWC levels (Figs. 2 and 4).

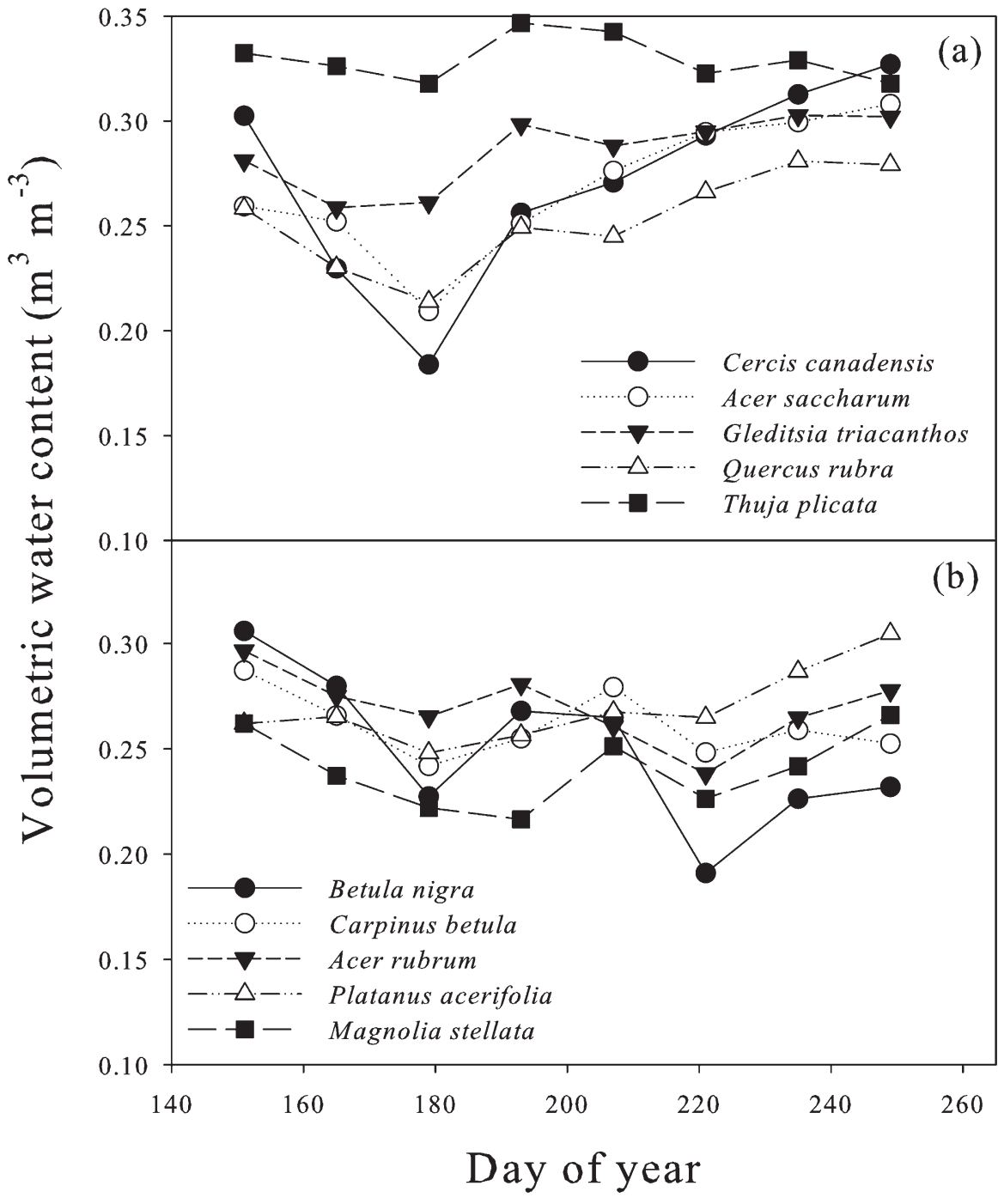

Fig. 3. Analysis of variance model estimates for volumetric water content $\left(\mathrm{m}^{3} \cdot \mathrm{m}^{-3}\right)$ of each species at each 2-week time period over the course of the study (May to September). Each species is depicted by an independent symbol and line defined on each panel (A or B). The significant interaction between species and time period is evident where lines deviate from parallel.
Changes in within-species variation over time caused dynamic shifts in the number of sensors required to accurately characterize a species at any specific time. Because of these fluctuations, two sets of recommendations were identified for the number of sensors necessary to accurately characterize each species to within $\pm 5 \%$ VWC (Table 2). The maximum value, ranging from 11 to 20 sensors, constrains the $95 \%$ CI to within $\pm 5 \%$ VWC for the entire study period, even on the most variable day. The mean value, ranging from six to 10 sensors among species, is an average of the daily sensor requirements for the study period. Although the mean values are approximately half the maximum values, they are suitable for $75 \%$ or greater of the study period in seven of the 10 species (Table 2).

Regardless of species, VWC increased linearly with increasing depth below the substrate surface (Fig. 5). The strong linear regression $\left(R^{2}=0.95\right)$ shows that the $20-\mathrm{cm}$ sensor measurement can be scaled along the vertical axis between 10 and $30 \mathrm{~cm}$ to provide a good approximation of the bulk container substrate moisture.

\section{Discussion}

Fluctuations in mean VWC over time may result from changes in evaporative demand (Fig. 2a) as well as total leaf area effects on the whole crown and canopy transpiring surface. As the significant interaction between species and time period suggests, these factors can interact with species-specific leaflevel physiology (e.g., the maximum rate of carboxylation) and morphology (e.g., leaf width) (Bauerle and Bowden, 2011a) to cause different rates of VWC change among species (Fig. 3). Consequently, even under identically irrigated conditions, the VWC of each species should be monitored separately.

Though estimates of mean VWC can fluctuate over time within a given species, changes in the amount of within-species variation directly affect the precision of those estimates. Although six of the 10 species showed an increase in within-species VWC variation over the course of the season, there was not a clear pattern of change among all species (Fig. 4). Moreover, changes in LAI and $\mathrm{ET}_{\mathrm{o}}$ over the course of the season did not explain the changes in within-species variation (Table 1; Fig. 2). Even though MAESTRA allowed us to isolate the interplay among variation in species leaf physiology and morphology variables affecting transpiration, the mechanistic modeling yielded an unexpected outcome; there was no evident relationship between within-species VWC variation and transpiration rates among our study species (Table 1). Thus, we did not find evidence to substantiate species-specific transpiration as a deterministic source of VWC variability among containers of the same species. The positive correlation in six species (Table 1) between GI and within-species VWC variation indicates a potential cause of increased within-species variation over time. Given that GI was more correlated to within-species 


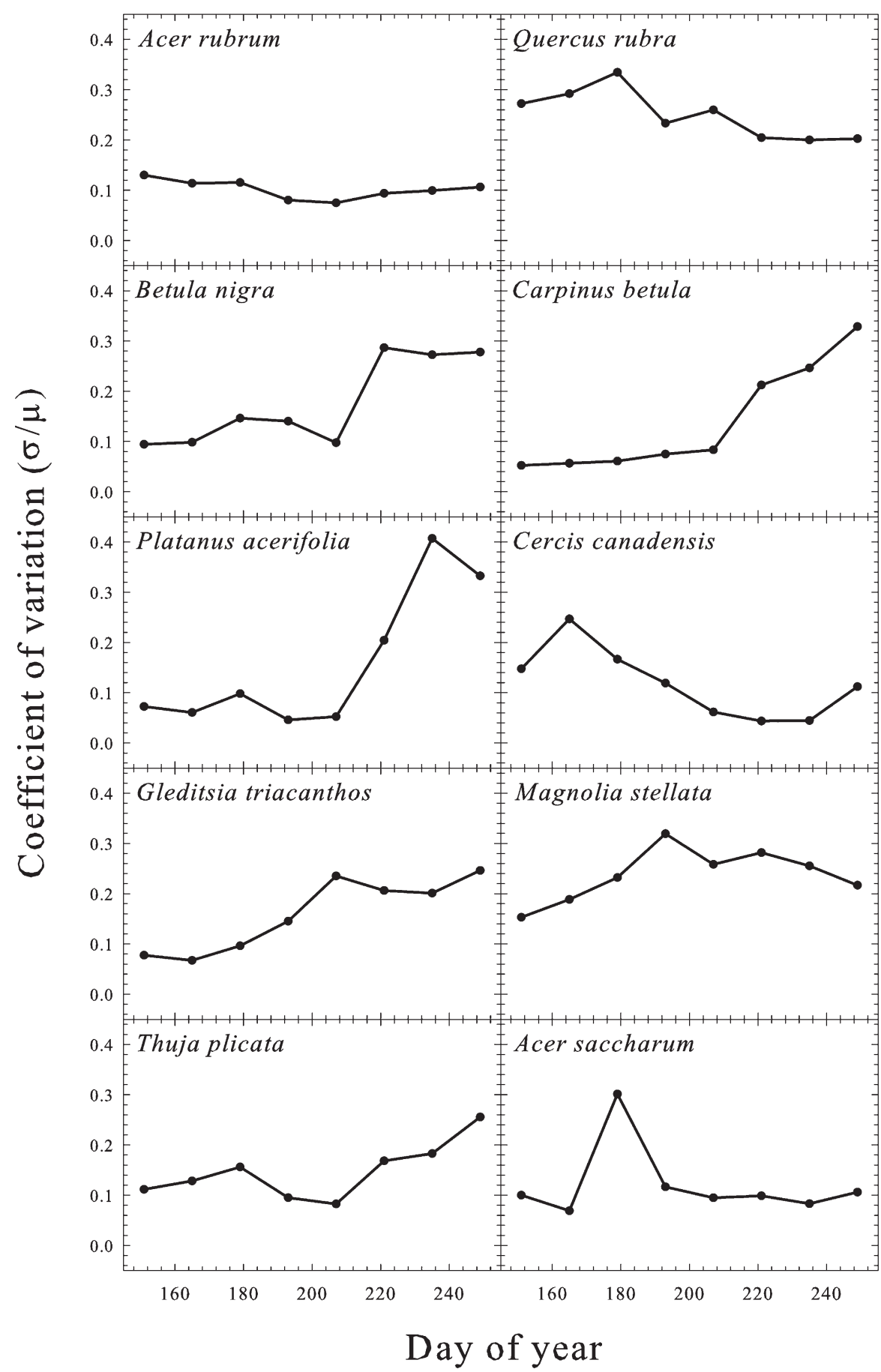

Fig. 4. Biweekly cv $(\sigma / \mu)$ for volumetric water content (VWC) plotted over the course of the study (May to September) for each species. Changes in variation over time directly affect the number of sensors required to estimate confidence intervals for VWC.

VWC variation than MAESTRA's transpiration estimates, it is possible that growth contributed to changes in within-species VWC variation through a mechanism other than transpiration.

Observations of the root systems at the end of the season indicated that all species had an abundance of roots throughout the entire container volume. Q. rubra in particular, possibly because of the extra year of growth relative to the other species, formed a tap root. However, regardless of the sensor location within the container (e.g., vertical moisture profile measurements), the density of roots made it difficult to remove the substrate moisture sensors. The observations were not quantitative, but they suggest that the increase in within-species VWC variation over time could be caused by root system development. This is supported by research showing changes in plant-available water as a consequence of root growth (Beeson, 2007). Because the root systems were observed only at the end of the study, it is dif- ficult to assess the rate of rooting and its exact relationship to variability in VWC. Although a considerable undertaking, we propose future research endeavors scrutinize root system development over the course of the season to examine density influences on VWC variation.

Regardless of the cause, the number of sensors needed to constrain the CI to $\pm 5 \%$ VWC changes as the variance fluctuates. From a precision standpoint, one could deploy enough sensors for even the most variable day of the study. However, we found that this could easily double the amount of sensors and thus substantially increase the measurement and material cost. The mean number of sensors, however, was suitable for at least $75 \%$ of the study period for seven of the 10 species and the majority of the study period for all 10 species. The mean sensor number may therefore be a practical compromise if cost concerns take precedence. Clearly, the decision to deploy enough sensors to constrain the CI to $\pm 5 \%$ VWC on the most variable day is the safest method to ensure precise estimates of VWC throughout the season. Like with many endeavors, however, a tradeoff exists between cost and precision.

Small differences in sensor placement along the vertical axis may contribute to variation in substrate moisture readings in a nursery pot-in-pot production setting (Bilderback, 2002). Therefore, it is important to place all sensors at identical depths within containers to ensure consistent estimates. We found a strong linear trend in VWC along the container depth profile. This indicates that the placement of a sensor in the vertical center of the container would linearly scale to other locations along the vertical axis (Fig. 5). Furthermore, the low SE of the mean among the 10 species indicates that the linear relationship persisted regardless of species. Based on this general linear trend, we conclude that a sensor placed at half the depth of the container (20 cm in this instance) is linearly scalable to most other depths within the container (between 10 and $30 \mathrm{~cm}$ in this study) and can be used to estimate bulk VWC of the container in substrates with similar properties. For other substrates, the exact trend of increasing VWC with depth could be affected by substrate physical properties, and the ideal depth of substrate moisture sensors may differ.

Although the 5TM sensors used in this study only measure a 0.3 -L volume of the container, they are an effective way to estimate water availability. The consistent vertical substrate moisture gradient shows sensors placed in the vertical center of the container could provide a good estimate of the average bulk moisture within the container, where the central location was the approximate average of the top and bottom values (Fig. 5). Some other sensors (e.g., Decagon Inc. Model 10HS) have a larger volume of influence (1.0 L) but still fail to measure the entire container moisture content. Moreover, individual sensors that might be able to capture the entire vertical profile of a container (e.g., Sentek Inc. Model EnviroSCAN) primarily measure within $10 \mathrm{~cm}$ of the probe and require an 
Table 1. Pearson's $R$ correlation coefficients from linear regressions of within-species variation in volumetric water content $\left(s_{v w c}\right)$ versus growth index, leaf area index, whole crown transpiration, transpiration per $\mathrm{m}^{2}$ leaf area, and reference evapotranspiration calculated from the FAO-56 Penman-Monteith equation.

\begin{tabular}{|c|c|c|c|c|c|}
\hline Species & $\begin{array}{l}\text { Vs. growth index } \\
\left(\mathrm{cm}^{2} \cdot \mathrm{m}^{-1}\right)\end{array}$ & $\begin{array}{l}\text { Vs. leaf area index } \\
\left(\mathrm{m}^{2} \cdot \mathrm{m}^{-2}\right)\end{array}$ & $\begin{array}{l}\text { Vs. whole crown } \\
\text { transpiration } \\
(\mathrm{kg} / \text { tree } / \mathrm{d})\end{array}$ & $\begin{array}{c}\text { Vs. transpiration per } \mathrm{m}^{2} \\
\text { leaf area } \\
\left(\mathrm{kg} \cdot \mathrm{m}^{2} \cdot \mathrm{d}^{-1}\right)\end{array}$ & $\begin{array}{c}\text { Vs. reference } \\
\text { evapotranspiration } \\
\left(\mathrm{mm} \cdot \mathrm{d}^{-1}\right)\end{array}$ \\
\hline Acer rubrum & -0.28 & 0.01 & -0.48 & -0.47 & -0.30 \\
\hline Quercus rubra & -0.65 & -0.59 & -0.49 & -0.39 & 0.21 \\
\hline Betula nigra & 0.75 & 0.77 & 0.44 & -0.64 & -0.20 \\
\hline Carpinus betula & 0.84 & 0.68 & 0.18 & 0.03 & -0.21 \\
\hline Platanus acerifolia & 0.74 & -0.64 & -0.55 & -0.01 & -0.25 \\
\hline Cercis canadensis & -0.42 & 0.18 & 0.38 & 0.06 & -0.08 \\
\hline Gleditsia triacanthos & 0.87 & 0.89 & 0.72 & 0.01 & -0.14 \\
\hline Magnolia stellata & 0.39 & 0.64 & 0.51 & 0.37 & 0.11 \\
\hline Thuja plicata & 0.75 & -0.02 & -0.19 & -0.24 & -0.19 \\
\hline Acer saccharum & 0.08 & -0.61 & -0.16 & 0.24 & 0.26 \\
\hline Average & 0.31 & 0.13 & 0.04 & -0.10 & -0.08 \\
\hline
\end{tabular}

Table 2. Recommended number of Decagon 5TM substrate moisture sensors to constrain the $95 \%$ confidence interval for volumetric water content $\left(\mathrm{m}^{3} \cdot \mathrm{m}^{-3}\right)$ to within $\pm 5 \%{ }^{\mathrm{z}}$

\begin{tabular}{lccc}
\hline Species & Mean sensors & Max. sensors & $\begin{array}{c}\text { Percent of study covered } \\
\text { by mean sensors }\end{array}$ \\
\hline Quercus rubra & 10 & 17 & $62 \%$ \\
Magnolia stellata & 9 & 15 & $55 \%$ \\
Thuja plicata & 8 & 20 & $75 \%$ \\
Carpinus betula & 8 & 17 & $76 \%$ \\
Gleditsia triacanthos & 8 & 16 & $78 \%$ \\
Platanus acerifolia & 7 & 18 & $78 \%$ \\
Betula nigra & 7 & 15 & $68 \%$ \\
Cercis canadensis & 7 & 14 & $78 \%$ \\
Acer saccharum & 6 & 14 & $82 \%$ \\
Acer rubrum & 6 & 11 & $97 \%$ \\
\hline
\end{tabular}

${ }^{z}$ Two recommendations are presented for each species: Mean sensors represents the mean number of sensors necessary over the course of the 4-month study (May to September), Max. sensors represents the number of sensors necessary on the most variable day of the study. The last column indicates the percentage of days during the study for which the mean number of sensors was adequate. Sensors were placed $20 \mathrm{~cm}$ below the substrate surface in the center of 57-L containers.

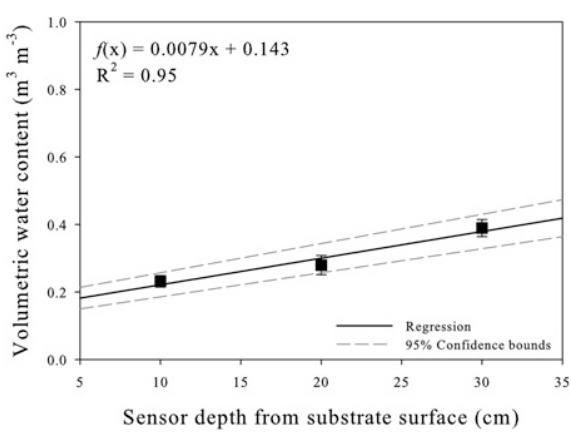

Fig. 5. Mean volumetric water content $\left(\mathrm{m}^{3} \cdot \mathrm{m}^{-3}\right)$ for the study period (May to September) at three substrate depths (solid squares with regression as solid line) and 95\% confidence bounds (hashed lines). Seasonal averages of all 10 species indicated a general linear trend of increasing volumetric water content (VWC) with increasing depth; error bars represent 1 SE $(n=10)$.

access tube. For this reason, a major disadvantage of almost all substrate moisture sensors is their limited capability to measure substrate moisture heterogeneity in the entire rhizosphere. From a practical standpoint, however, consistent sensor placement among containers is more important than a complete measurement of any one container when it comes to producing precise estimates of mean VWC.

\section{Conclusions}

Substrate moisture sensors coupled with wireless node networks make it possible to remotely monitor substrate moisture in realtime. Deployment of this technology in a container-grown intensive horticulture environment can inform precision irrigation decisions that save on water, labor, electricity, and fertilizer costs. At the same time, monitoring fluctuations in VWC over time can circumvent irrigation deficits that could cause water stress within a crop, probably resulting in a loss of potential growth. Management of leaching fractions by maintaining the substrate VWC below the substrate water-holding capacity could also reduce nutrient runoff, fungicide costs, disease incidence, and water contamination and/or consumption. To achieve these ends, estimates of mean substrate moisture must be precise, and substrate moisture sensors must be deployed with regard to the unique constraints of containerized production systems. Overall, we found that the optimum number of substrate moisture sensors, dictated by the amount of container to container variation in VWC, changed over time and differed among species.

\section{Literature Cited}

Andreu, L., J.W. Hopmans, and L.J. Schwankl. 1997. Spatial and temporal distribution of soil water balance for a drip-irrigated almond tree. Agr. Water Mgt. 35:123-146.

Ball, J.T., I.E. Woodrow, and J.A. Berry. 1987. A model predicting stomatal conductance and its contribution to the control of photosynthesis under different environmental conditions, p. 221224. In: Biggins, J. (ed.). Progress in photosynthesis research. Martinus Nijhoff Publishers, Dordrecht, The Netherlands.

Bauerle, W.L. and J.D. Bowden. 2004. A fiberoptic based system for integrating photosynthetically active radiation in plant canopies. HortScience 39:1027-1029.

Bauerle, W.L. and J.D. Bowden. 2011a. Separating foliar physiology from morphology reveals the relative roles of vertically structured transpiration factors within red maple crowns and limitations of larger scale models. J. Expt. Bot. 62:42954307.

Bauerle, W.L. and J.D. Bowden. 2011b. Predicting transpiration response to climate change: Insights on physiological and morphological interactions that modulate water exchange from leaves to canopies. HortScience 46:163166.

Bauerle, W.L., J.D. Bowden, M.F. McLeod, and J.E. Toler. 2004. Modeling intracrown and intracanopy interactions in red maple: Assessment of light transfer on carbon dioxide and water vapor exchange. Tree Physiol. 24:589_ 597.

Bauerle, W.L., J.D. Bowden, and G.G. Wang. 2007. The influence of temperature on withincanopy acclimation and variation in leaf photosynthesis and respiration: Spatial acclimation to microclimate gradients among thermally divergent Acer rubrum L. genotypes. J. Expt. Bot. 58:3285-3298

Bauerle, W.L., J.D. Bowden, G.G. Wang, and M.A Shahba. 2009. Exploring the importance of within-canopy spatial temperature variation on transpiration predictions. J. Expt. Bot. 60:36653676.

Bauerle, W.L., C.J. Post, M.E. McLeod, J.B. Dudley, and J.E. Toler. 2002. Measurement and modeling of the transpiration of a temperate red maple container nursery. Agr. For. Meteorol. 114:45-57.

Beeson, R.C. 2007. Determining plant-available water of woody ornamentals in containers in situ during production. HortScience 42:17001704.

Bilderback, T.E. 2002. Water management is key to reducing nutrient runoff from container nurseries. HortTechnology 12:541-544.

Bowden, J.D. and W.L. Bauerle. 2008. Measuring and modeling the variation in species specific transpiration in temperate deciduous hardwoods. Tree Physiol. 28:1675-1683. 
Coelho, E.F. and D. Or. 1998. Root distribution and water uptake patterns of corn under surface and subsurface drip irrigation. Plant Soil 206:123136.

Farquhar, G.D. and S. von Caemmerer. 1982. Modeling of photosynthetic response to environmental conditions, p. 550-587. In: Lange, O.L., P.S. Nobel, C.B. Osmond, and H. Ziegler (eds.). Physiological plant ecology II. Encyclopedia of plant physiology. Vol. 12B, New Series. Springer-Verlag, Heidelberg, Germany.

Hupet, F. and A. Vanclooster. 2005. Micro-variability of hydrological processes at the maize row scale: Implications for soil water content measurements and evapotranspiration estimates. J. Hydrol. (Amst.) 303:247-270.

Klute, A. (ed.). 1986.Methods of soil analysis. Part 1. Physical and mineralogical methods. 2nd Ed. Amer. Soc. Agron., Madison, WI.
Medlyn, B.E., D.A. Pepper, A.P. O'Grady, and H. Keith. 2007. Linking leaf and tree water use with an individual-tree model. Tree Physiol. 27:1687-1699.

Ott, R.L. and M. Longnecker. 2001. An introduction to statistical methods and data analysis. 5th Ed. Duxbury, Pacific Grove, CA.

Reynolds, R.F., W.L. Bauerle, and Y. Wang. 2009 Simulating carbon dioxide exchange rates of deciduous tree species: Evidence for a general pattern in biochemical changes and water stress response. Ann. Bot. (Lond.) 104:775-784.

Rundel, P.W., E.A. Graham, M.F. Allen, J.C. Fisher, and T.C. Harmon. 2009. Environmental sensor networks in ecological research. New Phytol. 182:589-607.

Starr, J.L. and I.C. Paltineanu. 2002. Capacitance devices, p. 463-474. In: Dane, J.H. and G.C. Topp (eds.). Methods of soil analysis. Part 4. Physical methods. Soil Sci. Soc. Amer., Madison, WI.
Vereecken, H., J.A. Huisman, H. Bogena, J. Vanderborght, J.A. Vrugt, and J.W. Hopmans. 2008. On the value of soil moisture measurements in vadose zone hydrology: A review. Water Resour. Res. 44:W00D06.

Wang, Y.P. and P.G. Jarvis. 1990a. Description and validation of an array model-MAESTRO. Agr. For. Meteorol. 51:257-280.

Wang, Y.P. and P.G. Jarvis. 1990b. Influence of crown structural properties on PAR absorption, photosynthesis, and transpiration in Sitka spruce: Application of a model (MAESTRO). Tree Physiol. 7:297-316.

Williams, D.J. 1978. Handling plants in landscape containers. J. Arbor. 4:184-186.

Yeager, T., D. Fare, C. Gilliam, J. Lea-Cox, A. Niemiera, J. Ruter, K. Tilt, S. Warren, T. Whitwell, and R. Wright. 2007. Best management practices: Guide for producing container-grown plants. 2nd Ed. Southern Nurs. Assoc., Atlanta, GA 